\title{
T-CELL RECEPTOR COMPLEX DEFICIENCY
}

\author{
Jose R. Regueiro and Maria J. Recio
}

\section{CONCISE DESCRIPTION AND BRIEF HISTORICAL OVERVIEW}

Mature T lymphocytes detect the presence of antigens by way of a variable surface heterodimer (either $\alpha \beta$ or $\gamma \delta$ ) termed the T-cell receptor (TCR, Fig. 11.1). In humans, TCR molecules form a complex with two invariant heterodimers called CD3 $\gamma \varepsilon$ and $C D 3 \delta \varepsilon$ and a single invariant homodimer termed CD247 (also called $\zeta \zeta$ ) (Call et al., 2002). These invariant proteins participate in assembly and surface expression of the whole TCR complex, and in the delivery of intracellular signals that drive $\mathrm{T}$-cell maturation or apoptosis in the thymus, and T-cell activation, proliferation, and effector function or anergy/apoptosis after antigen recognition (Malissen et al., 1999). During early T-cell development, other invariant chains such as the pre-TCR may assist immature TCR ensembles. CD3 and CD247 chains lack intrinsic enzymatic activity for signal transduction. Rather, they relay on conformationand phosphorylation-dependent recruitment and activation of a number of cytosolic and transmembrane protein tyrosine kinases (PTK) and adaptors such as Zap-70, Fyn, Lck, TRIM, LAT, SLP-76, SIT, and Nck (Schraven et al., 1999). Most TCR $\alpha \beta$-bearing T cells recognize processed peptides associated with major histocompatibility complex (MHC) molecules, whereas the ligands of TCR $\gamma \delta$-bearing T cells are still debated, but include unprocessed bacterial phosphoantigens in humans (Hayday, 2000).

Because of the central role of $\mathrm{T}$ cells in adaptive immune responses and the central role of the TCR complex in T-cell selection and function, the description in 1986 of a human familial CD3 expression deficiency in a child with immunodeficiency, but also in his healthy sibling, was in many ways surprising (Regueiro et al., 1986). Four years later, a second CD3 expression deficiency was reported in a healthy child
(Thoenes et al., 1990). As it turned out, the former was due to a complete CD3 $\gamma$ deficiency (Arnaiz-Villena et al., 1992) and became the first primary TCR complex immunodeficiency for which the genetic basis was elucidated, while the latter was caused by a partial CD $3 \varepsilon$ deficiency (Soudais et al., 1993). Further CD3, CD247, and TCR deficiencies followed (Table 11.1), which, keeping with the initial observations, can be classified as complete or partial (also termed leaky) according to the absence or presence of residual levels of the affected protein.

TCR complex deficiencies in humans are very rare autosomal recessive diseases characterized by a selective TCR complex expression defect frequently associated with peripheral blood T, but not B or natural killer (NK), lymphocytopenia and severe combined immunodeficiency disease (SCID) symptoms. TCR complex deficiencies are caused by a range of severe or leaky mutations in the genes encoding for TCR complex chains (to date other than TCR $\beta$, TCR $\gamma$ or TCR $\delta$ ). Mutation databases have been established for most of them (http://bioinf.uta.fi/base_root/index.php), as well as diagnostic support websites (http://bioinf.uta.fi/IDdiagnostics).

\section{CLINICAL AND PATHOLOGICAL MANIFESTATIONS}

Reported cases of TCR complex deficiencies have steadily grown to close to 30 patients in 16 families (see Table 11.1), half of them CD3 $\delta$ deficiencies. Age of onset is generally within the first year of life, essentially with SCID features such as recurrent respiratory infections, chronic diarrhea, and failure to thrive. Chronic pyogenic infections, dysmorphic features, or bone abnormalities were not reported. Unless hematopoietic stem cell transplantation is performed, most 


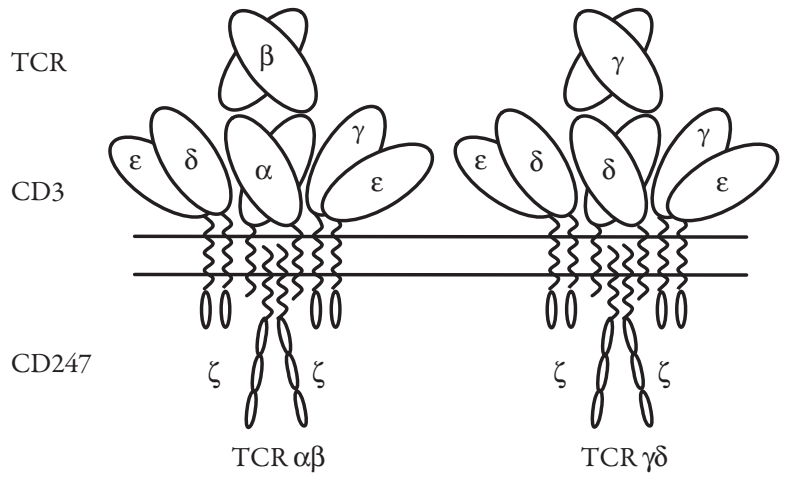

Figure 11.1 TCR complex isotypes. Variable TCR heterodimers bind antigens, while invariant CD3 heterodimers ( $\gamma \varepsilon$ and $\delta \varepsilon$ ) and CD247 homodimers (also called $\zeta \zeta$ ) undergo conformational changes and recruit intracellular enzymes (such as Fyn, Lck, and Zap) to initiate signal transduction.

patients die early in life as a consequence of viral infections. Omenn syndrome features (hypereosinophilia, hyper-IgE, dermatitis) have been reported in partial CD $3 \delta, C D 247$, or TCR $\alpha$ defects. In a few cases, notably in complete CD3 $\gamma$ deficiency and in a partial CD $3 \varepsilon$ deficiency, certain individuals do not show features of immunodeficiency and have reached their third decade in good health without intervention.

\section{LABORATORY FINDINGS}

The most consistent laboratory finding is a selective $\mathrm{T}$ lymphocytopenia. It may be severe $\left(\mathrm{T}^{\mu} \mathrm{B}^{+} \mathrm{NK}^{+}\right.$immunophenotype), as observed in complete CD $3 \varepsilon$ or CD $3 \delta$ defects, with less than $2 \%$ peripheral blood $\mathrm{T}$ cells, or mild $\left(\mathrm{T}^{+/ \mu} \mathrm{B}^{+} \mathrm{NK}^{+}\right)$, as observed in complete CD3 $\gamma$ or CD247 defects and in most partial TCR complex defects (with $>20 \%$ T cells, Table 11.2). Overall lymphocytopenia $(<3,000$ cells $/ \mu \mathrm{L}$ in children) is common in the former group, although exceptions due to compensatory B and NK expansions have been reported.
T-lymphocyte functions (anti-CD3 or phytohemagglutinin responses) and B-lymphocyte functions (antibody production following infection or vaccination) are absent when no $\mathrm{T}$ cells are detected, although Ig levels may be normal. These functions may be preserved or even normal in partial defects. Autoimmunity and/or immune dysregulation laboratory features may be present, particularly in such leaky defects (see information about Omenn syndrome above).

When $\mathrm{T}$ lymphocytes are present, the following laboratory findings have been reported:

1. A TCR complex expression defect is always observed, with 2- to 100-fold less TCR on patient versus normal control T cells using standard CD $3 \varepsilon$-specific monoclonal antibodies. It may be severe (more than 10 -fold), as observed in CD247 or (partial) CD $3 \varepsilon$ defects, or mild (less than 5-fold), as observed in CD3 $\gamma$ or (partial) $\mathrm{CD} 3 \delta$ or TCR $\alpha$ defects. Thus, a different hierarchy for invariant chain dependence can be proposed for T-cell selection (CD $3 \varepsilon \geq \mathrm{CD} 3 \delta>\mathrm{CD} 3 \gamma \geq \mathrm{CD} 247$, see above) as compared with TCR complex expression when some $T$ cells are selected $(\mathrm{CD} 3 \varepsilon \geq \mathrm{CD} 247>\mathrm{CD} 3 \delta \geq \mathrm{CD} 3 \gamma)$. This suggests differential signaling versus structural roles of the different chains during T-cell development.

2. Both $\alpha \beta$ and $\gamma \delta$ T cells can be detected, but with a restricted repertoire, with few qualifying as recent thymus emigrants (measured using TCR Rearrangement Excision Circles or CD $45 \mathrm{RA}^{+} \mathrm{CD} 27^{+} \mathrm{T}$ cells). However, notable exceptions have been observed, such as partial CD3 $\delta$ and TCR $\alpha$ defects, which show a $\mathrm{T} \alpha \beta^{\mu} \mathrm{T} \gamma \delta^{+} \mathrm{B}^{+} \mathrm{NK}^{+}$ immunophenotype with a fairly normal $\gamma \delta$ T-cell compartment (Morgan et al, 2010, Gil et al, 2011).

3. In rare cases, two T-cell populations are detected: one with impaired TCR complex expression and a second with normal TCR complex expression (Rieux-Laucat et al., 2006). Somatic mutations that reverted to wild type in certain T-cell clones were found to explain these findings (see the section on mutations analysis below).

Table 11.1 TCR COMPLEX DEFICIENCIES

\begin{tabular}{|c|c|c|c|c|c|c|c|}
\hline \multicolumn{4}{|c|}{ TCR COMPLEX DEFICIENCIES } & \multicolumn{2}{|c|}{ REFERENCESA } & \multicolumn{2}{|c|}{ NUMBER OF } \\
\hline PROTEIN & GENE & CHR. & OMIM & COMPLETE & PARTIAL & FAMILIES & PATIENTS \\
\hline $\mathrm{CD} 3 \gamma$ & $C D 3 G$ & 11 & 186740 & $1-5$ & & 3 & 5 \\
\hline $\operatorname{CD} 3 \delta$ & $C D 3 D$ & 11 & 186790 & $6-9$ & 10 & 7 & 16 \\
\hline $\mathrm{CD} 3 \varepsilon$ & $C D 3 E$ & 11 & 186830 & 7 & 11 & 2 & 4 \\
\hline $\mathrm{CD} 247^{\mathrm{b}}$ & $C D 247$ & 1 & 186780 & 12 & 13 & 2 & 2 \\
\hline TCR $\alpha$ & $T R A C$ & 14 & 186880 & & 14 & 2 & 2 \\
\hline & & & & & Total & 16 & 29 \\
\hline
\end{tabular}

${ }^{2}{ }^{1}$ Arnaiz-Villena et al., 1992; ${ }^{2}$ Sanal, 1996; $;{ }^{3}$ van Tol et al., 1997; Allende, 2000; ${ }^{5}$ Recio, 2007; ${ }^{6}$ Dadi, $2003 ;{ }^{7}$ de Saint Basile et al., 2004; ${ }^{8}$ Takada, 2005; $;$ Marcus et al., 2011; ${ }^{10}$ Gil et al., 2011; ${ }^{11}$ Soudais, $1993 ;{ }^{12}$ Roberts, 2007; ${ }^{13}$ Rieux-Laucat et al., 2006 ${ }^{14}$ Morgan, 2011.

${ }^{\mathrm{b}}$ Also known as TCR $\zeta$ or $\mathrm{CD} 3 \zeta$ 


\section{MOLECULAR BASIS}

The lack of any invariant TCR complex chain has a profound impact on $\alpha \beta$ TCR, pre-TCR, and $\gamma \delta$ TCR expression and function. As these receptors are required for T-cell development, $\mathrm{T}$ lymphocytopenia ensues in patients, and adaptive immunity is impaired. Different invariant chains show different effects on T-cell selection, as shown in Figure 11.2, supporting the hierarchy indicated above $(\mathrm{CD} 3 \varepsilon \geq \mathrm{CD} 3 \delta>$ $\mathrm{CD} 3 \gamma \geq \mathrm{CD} 247)$. TCR $\alpha$ strictly associates to CD $3 \delta \varepsilon \mathrm{dim}-$ ers, whereas TCR $\beta$ has been shown to interact with $\gamma \varepsilon$ as well as $\delta \varepsilon$ dimers before CD247 associates to the TCR complex (Call et al., 2002). This may explain the differential effect of the lack of $\mathrm{CD} 3 \delta$ or $\varepsilon$, as compared to CD3 $\gamma$ (or CD247), on T-cell development, which is blocked in complete CD $3 \delta$ or $\varepsilon$ deficiency, but only impaired in human CD $3 \gamma$ or CD247 deficiency.

Table 11.2 TCR COMPLEX DEFICIENCIES: CLINICAL AND IMMUNOLOGICAL DATA

\begin{tabular}{|c|c|c|c|c|c|c|c|c|c|c|}
\hline \multicolumn{6}{|c|}{$\operatorname{CD} 3 \gamma$} & \multicolumn{5}{|c|}{$\operatorname{CD} 3 \varepsilon$} \\
\hline \multicolumn{2}{|l|}{ Family } & 1 & \multirow[t]{2}{*}{2} & \multicolumn{2}{|c|}{3} & Family & \multirow[t]{2}{*}{1} & \multicolumn{3}{|c|}{2} \\
\hline Nationality & \multicolumn{2}{|r|}{ Turkey } & & \multicolumn{2}{|c|}{ Spain } & Nationality & & \multicolumn{2}{|c|}{ French } & \\
\hline Patient/sex & P1 M & P2 M & P3 M & P4M & P5 M & Patient/sex & P1 M & P2 F & P3 M & P4F \\
\hline Consanguineous? & \multicolumn{3}{|c|}{ YES } & \multicolumn{2}{|c|}{ NO } & Consanguineous? & NO & \multicolumn{3}{|c|}{ YES } \\
\hline Mutation & \multicolumn{5}{|c|}{ Early protein truncation (EPT) } & Mutation (leaky) & $\begin{array}{c}\text { Exon } 7 \\
\text { skipping } \\
\text { (EPT) }\end{array}$ & \multicolumn{3}{|c|}{ Early protein truncation } \\
\hline Diagnosis at $(\mathrm{m})$ & 3 & 7 & 48 & 12 & 48 & Diagnosis at $(\mathrm{m})$ & 24 & $?$ & 1 & birth \\
\hline Present age $^{1}$ & †9 m & $\dagger 20 \mathrm{~m}$ & $18 \mathrm{y}$ & $\dagger 32 \mathrm{~m}$ & $28 \mathrm{y}$ & Present age $^{1}$ & $20 y$ & $+5 \mathrm{~m}$ & $+3 m$ & $\dagger 2 \mathrm{~m}$ \\
\hline $\mathrm{BMT}^{2}$ & No & ID & No & No & No & $\mathrm{BMT}^{2}$ & No & No & No & $\mathbf{H}$ \\
\hline $\begin{array}{l}\text { Lymphopenia (\% T } \\
\text { cells) }\end{array}$ & 29 & 39 & 40 & 35 & 43 & $\begin{array}{l}\text { Lymphopenia (\% T } \\
\text { cells) }\end{array}$ & $63 \%$ & $?$ & $?$ & $<1 \%$ \\
\hline Cause of death ${ }^{3}$ & Sepsis & Pneumonia & AW & $\begin{array}{c}\text { Pneumo- } \\
\text { nia }\end{array}$ & AW & Cause of death ${ }^{3}$ & AW & $\begin{array}{l}\text { Pneu- } \\
\text { monitis }\end{array}$ & CMV & ADV \\
\hline \multicolumn{6}{|c|}{${ }^{1} 2009$ †=exitus at; $y$ (years); m (months) } & \multicolumn{5}{|c|}{${ }^{1} 2009$ y (years); m (months); ND (not done) } \\
\hline \multicolumn{6}{|c|}{${ }^{2}$ ID (HLA-matched sibling) } & \multicolumn{5}{|l|}{${ }^{2} \mathrm{H}$ (haploidentical) } \\
\hline \multicolumn{6}{|l|}{${ }^{3} \mathrm{AW}$ (alive and well) } & \multicolumn{5}{|c|}{${ }^{3} \mathrm{AW}$ (alive and well); ADV (adenovirus); CMV (cytomegalovirus) } \\
\hline
\end{tabular}

$\operatorname{CD} 3 \delta$

\begin{tabular}{|c|c|c|c|c|c|c|c|c|c|c|c|c|}
\hline Family & \multicolumn{5}{|c|}{1} & \multicolumn{2}{|c|}{2} & 3 & \multicolumn{2}{|c|}{4} & 5 & 6 \\
\hline Nationality & \multicolumn{5}{|c|}{ Canada Mennonites } & \multicolumn{3}{|c|}{ France } & \multicolumn{2}{|c|}{ Japan } & \multicolumn{2}{|c|}{ Ecuador } \\
\hline Patient/sex & $1 \mathrm{~F}$ & $2 \mathrm{M}$ & $3 \mathrm{M}$ & $4 \mathrm{~F}$ & $5 ?$ & $6 \mathrm{~F}$ & $7 \mathrm{~F}$ & $8 \mathrm{M}$ & $9 \mathrm{~F}$ & $10 \mathrm{M}$ & $11 \mathrm{M}$ & $12 \mathrm{M}$ \\
\hline Consanguineous? & \multicolumn{8}{|c|}{ YES } & \multicolumn{4}{|c|}{ NO } \\
\hline Mutation & \multicolumn{8}{|c|}{ Early protein truncation (exon $2 / 3$ ) } & \multicolumn{2}{|c|}{ Exon 3 skip } & \multicolumn{2}{|c|}{ Exon 2 skipping } \\
\hline Diagnosis at $(\mathbf{m})$ & 0 & 2 & 2 & $?$ & $?$ & 3 & 0 & 5 & 3 & 0 & 14 & 4 \\
\hline Present age $^{1}$ & $8 y$ & $\dagger 2 \mathrm{~m}$ & $\dagger 3 \mathrm{~m}$ & $>17 y^{4}$ & $?$ & $+5 \mathrm{~m}$ & $\dagger 6 \mathrm{~m}$ & $+6 \mathrm{~m}$ & $\dagger 3 \mathrm{~m}$ & $3 y$ & $19 \mathrm{~m}$ & $+5 \mathrm{~m}$ \\
\hline $\mathrm{BMT}^{2}$ & MUD & No & No & MUD & MUD & No & $\mathrm{H}$ & $\mathrm{H}$ & MUD & $\mathrm{CB}$ & $\mathrm{H}$ & MUD \\
\hline $\begin{array}{l}\text { Lymphopenia (\% T } \\
\text { cells) }\end{array}$ & & $.1-0.6 \%$ & & $?$ & $?$ & & & $0 \%$ & $1.7 \%$ & $0.1 \%$ & $14 \%$ & $30 \%$ \\
\hline Cause of death ${ }^{3}$ & $\mathrm{AW}$ & ADV & CMV & AW & AW & CMV & Asperg & EBV & CMV & AW & AW & CMV? \\
\hline
\end{tabular}

${ }^{1} \mathrm{y}$ (years); $\mathrm{m}$ (months)

${ }^{2}$ MUD (marrow unrelated donor); H (haploidentical); CB (cord blood)

${ }^{3} \mathrm{AW}$ (alive and well); ADV (adenovirus); CMV (cytomegalovirus); EBV (Epstein-Barr virus); Asperg (Aspergillus)

${ }^{4} \mathrm{Had}$ a healthy baby in 2008

(continued) 
Table 11.2 (CONTINUED)

\begin{tabular}{|c|c|c|c|c|}
\hline \multicolumn{3}{|c|}{$\mathrm{CD} 247$} & \multicolumn{2}{|c|}{$\operatorname{TCR} \alpha$} \\
\hline Family & 1 & 2 & 1 & 2 \\
\hline Nationality & Caribbean & Hawaii & \multicolumn{2}{|c|}{ Pakistani } \\
\hline Patient/sex & P1 M & P2 F & $1 \mathrm{~F}$ & $2 \mathrm{M}$ \\
\hline Consanguineous & $?$ & NO & \multicolumn{2}{|c|}{ YES } \\
\hline Mutation (leaky) & Early truncation & Late insertion & \multicolumn{2}{|c|}{ Exon 3 skipping } \\
\hline Diagnosis at (m) & 4 & 10 & 15 & 6 \\
\hline Present age & $8 y$ & $10 \mathrm{y}$ & $?$ & $?$ \\
\hline BMT & Haploidentical & Haploidentical & Haploidentical & Haploidentical \\
\hline $\begin{array}{l}\text { Lymphopenia (\% CD3 } 3^{\text {dull }} \\
\text { T cells) }\end{array}$ & $4-17 \%$ & $63 \%$ & $21 \%$ & $50 \%$ \\
\hline Cause of death & Alive \& well & Alive \& well & Alive \& well & Alive \& well \\
\hline
\end{tabular}

\section{FUNCTIONAL ASPECTS}

TCR complex function obviously cannot be studied in patients with TCR complex defects that block T-cell development. When some $T$ cells are present, meaningful comparisons with normal individuals are difficult because $\mathrm{T}$-cell subset representation and surface TCR complex expression are altered. Nonetheless, it is clear that normal TCR signaling is possible in vivo, since selection took place in those patients and in some cases $(\mathrm{CD} 3 \gamma$, partial CD3 $\varepsilon$ ) normal antibody responses indicate intact helper T-cell functions. T-cell lines from patients have been difficult to derive. Our studies in human CD3 $\gamma$-deficient primary $\mathrm{T}$ cells, interleukin (IL)-2-dependent T-cell lines, and Herpesvirus saimiri- or HTLV-I-transformed T lymphocytes indicated that $\mathrm{CD} 3 \gamma$ contributes to but is not required for the regulation of TCR trafficking in resting and antigen-stimulated mature T lymphocytes (Torres et al., 2003). Despite its effects on TCR complex expression (likely due to impaired recycling), CD $3 \gamma$ is dispensable for several TCR-induced mature T-cell

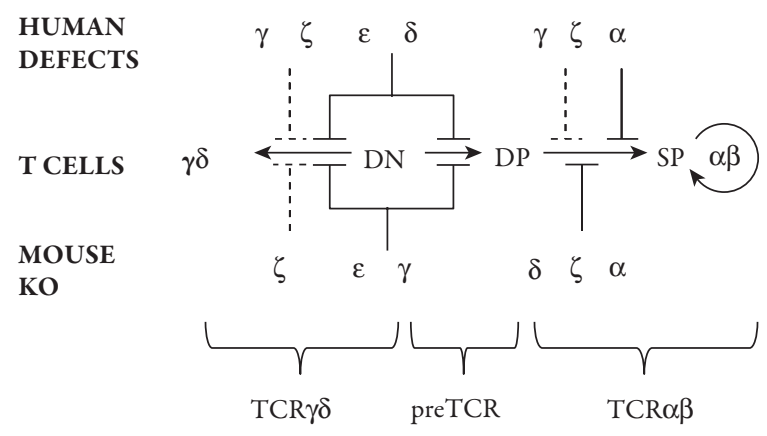

Figure 11.2 Leaky (dashed) or severe (solid) block of early T-cell differentiation caused by complete invariant TCR complex chain defects in humans or mice. $\alpha \beta$ T-cell development is simplified in two steps: (1) pre-TCR-mediated double-negative (DN) CD4-CD8- to double-positive $\left(\mathrm{DP}, \mathrm{CD}^{+} \mathrm{CD}^{+}\right)$transition and (2) $\alpha \beta$ TCR-mediated positive/negative selection and generation of single-positive (SP) $\mathrm{CD}^{+}$ and $\mathrm{CD}^{+} \alpha \beta$ T cells. $\gamma \delta \mathrm{T}$ cells develop from DN thymocytes. CD247 is depicted as $\zeta$ for brevity. responses, such as calcium flux, cytotoxicity, up- or downregulation of several surface molecules, and proliferation and synthesis of certain cytokines (TNF $\alpha$ ). In contrast, phorbol myristate acetate-induced TCR complex downregulation and TCRinduced synthesis of other cytokines (IL-2) as well as adhesion and polarization were severely impaired (Arnaiz-Villena et al., 1992; Pacheco-Castro et al., 1998; Perez-Aciego et al., 1991; Torres et al., 2002). The lack of CD $3 \gamma$ causes a stronger impairment of $\alpha \beta$ TCR expression in $\mathrm{CD}^{+}$than in $\mathrm{CD} 4^{+} \mathrm{T}$ cells in humans and in mice. We have shown that this is due to biochemical differences in the intracellular control of $\alpha \beta T C R$ complex assembly, maturation, or transport between the two lineages, which result in conformational lineage-specific differences regulated by activation or differentiation both in normal and in CD3 $\gamma$-deficient primary T cells (Zapata et al., 1999, 2004). More recently, we have reported that the lack of CD $3 \gamma$ in humans caused a stronger impairment of CD3 expression in $\alpha \beta$ than in $\gamma \delta$ T cells (Siegers et al., 2007), whereas the opposite is true in partial CD3 $\delta$ deficiency (Gil et al, 2011).

\section{MUTATION ANALYSIS}

Mutation analysis was started by probing T-cell RNA with $C D 3, C D 247$, or TRAC-specific sequences. For some CD $3 \delta$ defects, microarray analysis of thymocyte RNA revealed low specific transcript levels. In all cases, cDNA was synthesized and used to amplify and sequence TCR complex genes. This revealed the presence of point mutations or small deletions (Fig. 11.3), which could be traced with mutation-specific oligonucleotides, restriction enzymes, or direct sequencing. Small deletions were due to splicing site mutations, which were identified on genomic DNA by sequencing relevant exon boundaries. As a consequence, no or very few specific proteins of the TCR complex could be detected biochemically.

In a partial CD247 deficiency, reversion of some T-cell clones to normal expression was observed in vivo as a consequence of additional mutations in T-cell precursors (Rieux-Laucat et al., 2006). 


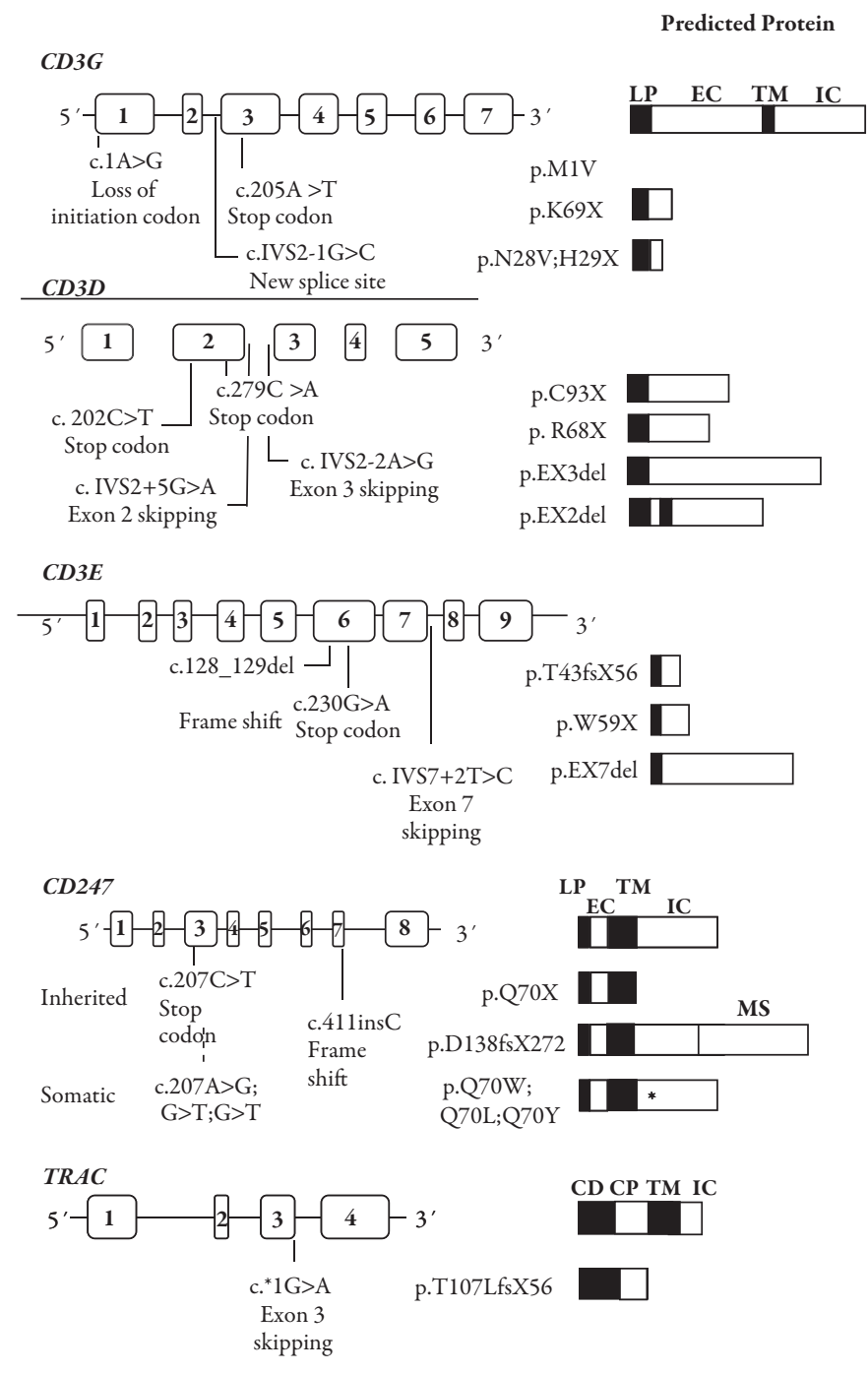

Figure 11.3 Mutations reported in genes encoding for TCR complex chains and predicted proteins. LP, leader peptide; EC, extracellular; TM, transmembrane; IC, intracellular; $\mathrm{CD}$, constant domain; $\mathrm{CP}$, connecting peptide; UT, untranslated.

\section{STRATEGIES FOR DIAGNOSIS}

Definitive: Male or female patient with surface TCR complex expression defect, selective peripheral blood T lymphocytopenia $\left(\mathrm{T}^{-} \mathrm{B}^{+} \mathrm{NK}^{+}\right.$or $\mathrm{T}^{+/-} \mathrm{B}^{+} \mathrm{NK}^{+}$phenotype), and mutations in a TCR complex gene (such as $C D 3 G, C D 3 D, C D 3 E, C D 247$, or TRAC).

Probable: Male or female patient with surface TCR complex expression defect and selective peripheral blood $\mathrm{T}$ lymphocytopenia $\left(\mathrm{T}^{-} \mathrm{B}^{+} \mathrm{NK}^{+}\right.$or $\mathrm{T}^{+-} \mathrm{B}^{+} \mathrm{NK}^{+}$phenotype)

Spectrum of disease: From SCID (common) to healthy (rare, overlooked?). Complete $\mathrm{CD} 3 \varepsilon$ or $\mathrm{CD} 3 \delta$ defects show the $\mathrm{T}^{-} \mathrm{B}^{+} \mathrm{NK}^{+}$phenotype, whereas complete $\mathrm{CD} 3 \gamma$ or $\mathrm{CD} 247$ defects and partial defects tend to show the $\mathrm{T}^{+/-} \mathrm{B}^{+} \mathrm{NK}^{+}$phenotype. T-cell revertants with normal TCR complex expression due to somatic mutations may be present.

Differential diagnosis: With patients showing $\mathrm{T}^{-} \mathrm{B}^{+} \mathrm{NK}^{+}$or $\mathrm{T}^{+/-} \mathrm{B}^{+} \mathrm{NK}^{+}$phenotypes, such as those with defects in IL7R $\alpha$,
FOXN1, Coronin-1A, Zap70, MHC class I or II, PNP, ADA, or DiGeorge syndrome

Testing for the percentage of $\mathrm{CD}^{+}$lymphocytes may not be enough to detect TCR complex deficiencies, particularly when some T cells are present. Analyzing the mean fluorescence intensity is mandatory, as well as using a range of TCR-, CD3-, and CD247-specific monoclonals. The expression defect follows the $\mathrm{CD} 3 \varepsilon \geq \mathrm{CD} 247>\mathrm{CD} 3 \delta \geq \mathrm{CD} 3 \gamma$ hierarchy with a wide fold-difference range.

Biopsy specimens from lymphoid tissues should be thoroughly studied (Arnaiz-Villena et al., 1991; Dadi et al., 2003; Morgan et al., 2011) and T cells preserved if possible (Pacheco et al., 1998; Perez-Aciego et al., 1991) and analyzed by immunoprecipitation (Perez-Aciego et al., 1991; Thoenes et al., 1992) and molecular biology techniques (Arnaiz-Villena et al., 1992; Soudais et al., 1993).

\section{MODE OF INHERITANCE, CARRIER DETECTION, AND PRENATAL DIAGNOSIS}

TCR complex deficiencies are autosomal recessive disorders. Heterozygotes are healthy and cannot be easily distinguished from normals by standard laboratory tests, although half-normal CD3 expression levels have been reported by flow cytometry (Brooimans et al., 2000; Muñoz-Ruiz et al., 2013) or biochemistry (van Tol et al., 1997). Thus mutation analysis must be performed in each case, as explained above. Restriction fragment length polymorphism (RFLP) analysis using TaqI and a $C D 3 E$ probe ( $50 \%$ heterozygosity) or polymorphic markers may help to define CD3GDE haplotype inheritance for carrier detection and/or prenatal diagnosis, since recombination within the $C D 3$ gene complex is rare.

\section{TREATMENT AND PROGNOSIS}

Unless the patient is transplanted, the prognosis is very poor for those with complete defects except $\mathrm{CD} 3 \gamma$ and for most partial defects (see Table 11.2). Matched related, haploidentical mismatched related (MMRD), matched unrelated (MUD), and mismatched unrelated donors have all been used for hematopoietic stem cell transplantation, with bone marrow, peripheral blood, or cord blood as sources. The recipients generally underwent myeloablative conditioning. The largest series consisted of patients with $\mathrm{CD} 3 \delta$ defects; they showed a superior outcome using MUD as compared to MMRD (Marcus et al, 2011). Viral infections (herperviruses) are the most common cause of death among transplanted patients. Successfully transplanted patients have been shown to lead a normal life up to 18 years posttransplantation.

A few patients had no immunodeficiency symptoms and thus did not receive hematopoietic stem cell transplantation $(\mathrm{CD} 3 \gamma$, partial CD3E), reaching their third decade in good health. In those cases prophylactic intravenous immunoglobulin (IVIG) with (Le Deist et al., 1991) or without (van Tol et al., 1997) antibiotics were used, or antibiotics only when symptoms developed (Allende et al, 2000). The observation 
that most antibody responses were normal in vivo in one case prompted a comprehensive vaccination program, excluding attenuated live viruses. No secondary effects were recorded. Thus, this approach may be helpful for other TCR complexdeficient patients on a preventive basis. Bronchial asthma in one case was treated with ketotifen and cromolyn sodium between 3.5 and 7 years of age (Sanal et al., 1996), followed by salbutamol sulfate and sodium chromoglycate to manage his nonatopic hyperreactive airway, including eformoterol with occasionally inhaled steroids. Gene therapy protocols were tested in vitro (Sun et al., 1997). However, transfer of $\mathrm{CD} 3 \gamma$ into mature $\mathrm{T}$ cells may disrupt their intrathymic fine tuning (Pacheco-Castro et al., 2003). Thus, lymphoid progenitors may be better targets in this case, although the selective advantage of transduced over untransduced $\mathrm{T}$ cells remains to be established.

\section{ANIMAL MODELS}

Single as well as multiple TCR complex deficiencies have been created in mice through gene targeting (Malissen et al., 1999; Mombaerts et al., 1992). Ablation of any invariant TCR complex protein essentially blocked T-cell development, although at different intrathymic checkpoints, and to a different extent (see Fig. 11.2). Indeed, all invariant TCR complex proteins, except $\mathrm{CD} 3 \delta$, are required for T-cell selection at the pre-TCR (TCR $\beta$ ) checkpoint, with the following hierarchy: CD $3 \varepsilon>$ CD $3 \gamma>$ CD247. However, all invariant TCR complex chains, including $\mathrm{CD} 3 \delta$, are required for T-cell selection at the TCR $\alpha \beta$ checkpoint and for $\alpha \beta$ TCR surface expression. Interestingly, $\mathrm{CD} 3 \delta$ is also dispensable for $\gamma \delta$ T-cell selection and for $\gamma \delta$ TCR surface expression in mice, but not in humans (Dadi et al., 2003). This is due to a differential stoichiometry of the $\gamma \delta$ TCR between the species (Siegers et al., 2007). The mouse surface $\gamma \delta$ TCR does not incorporate the $\mathrm{CD} 3 \delta$ subunit; thus, its stoichiometry is TCR $\gamma \delta \mathrm{CD} 3 \varepsilon \gamma \varepsilon \gamma \zeta \zeta$ rather than TCR $\gamma \delta C D 3 \varepsilon \delta \varepsilon \gamma \zeta \zeta$, as observed in humans (see Fig. 11.1). The murine models are similar to human CD3 deficiencies in some aspects $(\varepsilon>\gamma$ in $\alpha \beta$ TCR expression, no peripheral T cells when CD3 $\delta$ is lacking) but not in others (peripheral blood T-lymphocyte numbers are clearly higher in humans lacking CD3 $\gamma$ ). Thus, peripheral lymphoid expansion mechanisms may differ between species. CD3 gene inactivation in mice, even when kept in pathogen-free facilities, may cause pathological manifestations, including enteropathy in $\zeta / \eta$ - or CD3 $\delta$-deficient mice, which resemble those observed in some $\mathrm{CD} 3 \gamma$ - or $\mathrm{CD} 3 \delta$-deficient humans.

\section{CONCLUDING REMARKS}

The TCR complex is first expressed and used by T cells early during their intrathymic development. Accordingly, complete TCR complex deficiencies strongly impair early T-cell differentiation events in humans, generally causing SCID. TCR complex deficiencies provide insights into the redundant and unique roles of these transmembrane molecules for TCR complex assembly and signal transduction and thus for T-cell selection and antigen recognition, which are not always recapitulated by murine models.

\section{ACKNOWLEDGMENTS}

Grants by Ministerio de Economía y Competitividad (SAF2011-24235), Comunidad Autónoma de Madrid (S2011/BMD-2316), Fundación Lair, Instituto de Salud Carlos III(RIERRD08-0075-0002,PI080921)andFundación Mutua Madrileña have supported our work. We thank the following colleagues for updated/unpublished information in Table 11.2: Hidetoshi Takada (Department of Pediatrics, Graduate School of Medical Sciences, Kyushu University), Juana Gil (Inmunología, Hospital Gregorio Marañón, Madrid, Spain), Eduardo Lopez-Granados (Inmunología, Hospital La Paz, Madrid, Spain), Chaim M. Roifman (The Canadian Centre for Primary Immunodeficiency, Div. of Immunology and Allergy, The Hospital for Sick Children, Toronto, Ontario, Canada), and Françoise Le Deist (CHU Sainte-Justine, Montréal, Canada).

\section{REFERENCES}

Allende LM, Garcia-Perez MA, Moreno A, et al. Fourteen years' follow-up of an autoimmune patient lacking the CD3gamma subunit of the T-lymphocyte receptor. Blood 2000;96:4007-4008.

Arnaiz-Villena A, Perez-Aciego P, Ballestin C, et al. Biochemical basis of a novel $\mathrm{T}$ lymphocyte receptor immunodeficiency by immunohistochemistry: a possible CD3gamma abnormality. Lab Invest 1991;64:675-681.

Arnaiz-Villena A, Timon M, Corell A, et al. Brief report: primary immunodeficiency caused by mutations in the gene encoding the CD3-gamma subunit of the T-lymphocyte receptor. $N$ Engl J Med 1992;327:529-533.

Brooimans RA, Rijkers GT, Wulffraat NM, Zegers BJM. Severe combined immunodeficiency in a patient with defective expression of CD3. Exp Clin Immunobiol 2000;203:463.

Call ME, Pyrdol J, Wiedmann M, Wucherpfennig KW. The organizing principle in the formation of the T cell receptor-CD3 complex. Cell 2002; 11:967-979.

Dadi HK, Simon AJ, Roifman CM. Effect of CD3delta deficiency on maturation of alpha/beta and gamma/delta T-cell lineages in severe combined immunodeficiency N Engl J Med 2003;349:1821-1828.

De Saint Basile G, Geissmann F, Flori E, et al. Severe combined immunodeficiency caused by deficiency in either the delta or the epsilon subunit of CD3. J Clin Invest 2004;114:1512-1517.

Gil J, Busto EM, Garcillán B, et al. A leaky mutation in $C D 3 D$ differentially affects $\alpha \beta$ and $\gamma \delta$ T cells and leads to a $\mathrm{T} \alpha \beta^{-} \mathrm{T} \gamma \delta^{+} \mathrm{B}^{+} \mathrm{NK}^{+}$ human SCID. J Clin Invest 2011;121:3872-3876.

Hayday AC. Gamma delta cells: a right time and a right place for a conserved third way of protection. Annu Rev Immunol 2000;18:9751026.

Le Deist F, Thoenes G, Corado J, et al. Immunodeficiency with low expression of the $\mathrm{T}$ cell receptor/CD3 complex. Effect on T lymphocyte activation. Eur J Immunol 1991;21:1641-1647.

Malissen B, Ardouin L, Lin SY, Malissen M. Function of the CD3 subunits of the Pre-TCR and TCR complexes during T development. $A d v$ Immunol 1999;72:103-148.

Marcus N, Takada H, Law J, et al. Haematopoietic stem cell transplantation for CD3 $\delta$ deficiency. J Allergy Clin Immunol 2011;128:10501057. 
Mombaerts P, Clarke AR, Rudnicki MA et al. Mutations in T-cell antigen receptor genes alpha and beta block thymocyte development at different stages. Nature 1992;360(6401):225-231.

Muñoz-Ruiz M, Pérez-Flores V, Garcillán B, et al. Human CD3 $\gamma$, but not CD3 $\delta$, haploinsufficiency differentially impairs $\gamma \delta$ versus $\alpha \beta$ surface TCR expression. BMC Immunol 2013;14:3. doi:10.1186/1471-2172$14-3$.

Morgan NV, Goddard S, Cardno TS, et al. Mutation in the TCR $\alpha$ subunit constant gene (TRAC) leads to a human immunodeficiency disorder characterized by a lack of TCR $\alpha \beta+\mathrm{T}$ cells. J Clin Invest 2011;121(2):695-702.

Pacheco-Castro A, Martín JM, Millan R, et al. Toward gene therapy for human CD3 deficiencies. Hum Gene Therapy 2003;14:1653-1661.

Pacheco-Castro A, Zapata DA, Torres PS, Regueiro JR. Signaling through a CD3g-deficient TCR-CD3 complex in immortalized mature CD4+ and CD8+ T lymphocytes. J Immunol 1998;161:3152-3160.

Perez-Aciego P, Alarcon B, Arnaiz-Villena A, et al. Expression and function of a variant $\mathrm{T}$ cell receptor complex lacking CD3-gamma. J Exp Med 1991;174:319-326.

Recio MJ, Moreno-Pelayo MA, Kilic SS, et al. Differential biological role of CD3 chains revealed by human immunodeficiencies. I Immunol 2007; 178:2556-2564.

Regueiro JR, Arnaiz-Villena A, Ortiz de Landazuri M, et al. Familial defect of CD3 (T3) expression by T cells associated with rare gut epithelial cell autoantibodies. Lancet 1986; i:1274-1275.

Rieux-Laucat F, Hivroz C, Lim A, et al. Inherited and somatic CD3zeta mutations in a patient with T-cell deficiency. N Engl J Med 2006; 354: 1913-1921.

Roberts JL, Lauritsen JP, Cooney M, et al. T-B+NK+ severe combined immunodeficiency caused by complete deficiency of the CD3zeta subunit of the T-cell antigen receptor complex. Blood 2007;109:3198-3206.

Sanal O, Yel L, Ersoy F, et al. Low expression of the T-cell receptor-CD3 complex: a case with a clinical presentation resembling humoral immunodeficiency. Turk J Pediatr 1996;38:81-84.

Schraven B, Cardine AM, Hübener C, et al. Integration of receptor-mediated signals in $\mathrm{T}$ cells by transmembrane adaptor proteins. Immunol Today 1999;20:431-434.
Siegers GM, Swamy M, Fernandez-Malave E, et al. Different composition of the human and the mouse $\{$ gamma\} $\{$ delta $\} \mathrm{T}$ cell receptor explains different phenotypes of CD3\{gamma\} and CD3\{delta\} immunodeficiencies. J Exp Med 2007;204:2537-2544.

Soudais C, Villartay JP, Le Deist F, et al. Independent mutations of the human CD3-epsilon gene resulting in a $\mathrm{T}$ cell receptor/CD3 complex immunodeficiency. Nat Genet 1993;3:77-81.

Sun J, Pacheco-Castro A, Borroto A, et al. Construction of retroviral vectors carrying human $\mathrm{CD} 3$ gamma $\mathrm{cDNA}$ and reconstitution of CD3gamma expression and $\mathrm{T}$ cell receptor surface expression and function in a CD3-gamma deficient mutant T cell line. Hum Gene Ther 1997;8:1041-1048.

Takada H, Nomura A, Roifman CM, Hara T. Severe combined immunodeficiency caused by a splicing abnormality of the CD3delta gene. Eur $J$ Pediatr 2005; 164:311-314.

Thoenes G, Le Deist F, Fisher A, et al. Immunodeficiency associated with defective expression of the T-cell receptor-CD3 complex. $N$ Engl JMed 1990;322:1399.

Thoenes G, Soudais C, Le Deist F, et al. Structural analysis of low TCRCD3 complex expression in T cells of an immunodeficient patient. J Biol Chem 1992;267:487-493.

Torres PS, Alcover A, Zapata DA, et al. TCR dynamics in human mature T lymphocytes lacking CD3 gamma. J Immunol 2003;170:59475955.

Torres PS, Zapata DA, Pacheco-Castro A, et al. Contribution of CD3gamma to TCR regulation and signaling in human mature $\mathrm{T}$ lymphocytes. Int Immunol 2002; 14:1357-1367.

van Tol MJD, Sanal O, Langlois van den Bergh R, et al. CD3gamma chain deficiency leads to a cellular immunodeficiency with mild clinical presentation. Immunologist 1997(suppl. 1):41.

Zapata DA, Pacheco-Castro A, Torres PS, et al. Conformational and biochemical differences in the TCR.CD3 complex of CD8+ versus CD4+ mature lymphocytes revealed in the absence of CD3gamma. J Biol Chem 1999;274:35119-35128.

Zapata DA, Schamel WWA, Torres PS, et al. Biochemical differences in the $\alpha \beta$ TCR.CD3 surface complex between CD + and CD 4+ human mature T lymphocytes. J Biol Chem 2004;279:24485-24492. 